University of Nebraska - Lincoln

DigitalCommons@University of Nebraska - Lincoln

Nebraska Cooperative Fish \& Wildlife Research Nebraska Cooperative Fish \& Wildlife Research Unit -- Staff Publications

2006

\title{
Habitat Selection Responses of Parents to Offspring Predation Risk: An Experimental Test
}

\author{
J. J. Fontaine \\ University of Montana - Missoula, jfontaine2@unl.edu \\ T. E. Martin \\ University of Montana - Missoula, tom.martin@umontana.edu
}

Follow this and additional works at: https://digitalcommons.unl.edu/ncfwrustaff

Part of the Other Environmental Sciences Commons

Fontaine, J. J. and Martin, T. E., "Habitat Selection Responses of Parents to Offspring Predation Risk: An Experimental Test" (2006). Nebraska Cooperative Fish \& Wildlife Research Unit -- Staff Publications. 38. https://digitalcommons.unl.edu/ncfwrustaff/38

This Article is brought to you for free and open access by the Nebraska Cooperative Fish \& Wildlife Research Unit at DigitalCommons@University of Nebraska - Lincoln. It has been accepted for inclusion in Nebraska Cooperative Fish \& Wildlife Research Unit -- Staff Publications by an authorized administrator of DigitalCommons@University of Nebraska - Lincoln. 


\title{
Habitat Selection Responses of Parents to Offspring Predation Risk: An Experimental Test
}

\author{
J. J. Fontaine ${ }^{\star}$ and T. E. Martin ${ }^{\dagger}$
}

U.S. Geological Survey, Montana Cooperative Wildlife Research Unit, University of Montana, Missoula, Montana 59812

Submitted February 10, 2006; Accepted June 23, 2006; Electronically published October 31, 2006

ABSTRACT: The ability of nest predation to influence habitat settlement decisions in birds is widely debated, despite its importance in limiting fitness. Here, we experimentally manipulated nest predation risk across a landscape and asked the question, do migratory birds assess and respond to variation in nest predation risk when choosing breeding habitats? We examined habitat preference by quantifying the density and settlement date of eight species of migratory passerines breeding in areas with and without intact nest predator communities. We found consistently more individuals nesting in areas with reduced nest predation than in areas with intact predator assemblages, although predation risk had no influence on settlement or breeding phenology. Additionally, those individuals occupying safer nesting habitats exhibited increased singing activity. These findings support a causal relationship between habitat choice and nest predation risk and suggest the importance of nest predation risk in shaping avian community structure and breeding activity.

Keywords: habitat selection, breeding density, nest predation, nest initiation, song rate.

Habitat decisions by females of all taxa that choose where to rear offspring can influence individual reproductive success as well as population dynamics and community structure (Martin 1992, 1998; Smith et al. 2000; Kessler and Baldwin 2002; Blaustein et al. 2004; Tschanz et al. 2005). Resource limitation, predation, competition, and unfavorable climate all can influence offspring quality and survival (Casey 1976; Martin 1998, 2001; Kessler and Baldwin 2002). Theory predicts that females should choose sites to rear offspring that minimize these costs (Fretwell 1972; Jaenike and Holt 1991; Martin 1992, 1998; Morris 2003).

\footnotetext{
* Corresponding author; e-mail: fontaine.joseph@gmail.com.
}

† E-mail: tom.martin@umontana.edu.

Am. Nat. 2006. Vol. 168, pp. 811-818. (C) 2006 by The University of Chicago. 0003-0147/2006/16806-41636\$15.00. All rights reserved.
Risk of predation to offspring is thought to be particularly important to oviposition and nest site selection (Martin 1998, 2001; Kessler and Baldwin 2002; Blaustein et al. 2004). Predation risk at particular oviposition and nest sites, however, is highly influenced by variation in risk at larger spatial scales (Martin 1992; Rieger et al. 2004; Lloyd et al. 2005). Theory predicts that females should assess risk at these larger spatial scales and alter their settling decisions to maximize the potential for safe nesting locations locally (Fretwell 1972; Jaenike and Holt 1991; Martin 1992, 1998; Morris 2003), but few empirical studies have tested this prediction.

Variation in avian nest predation risk at the landscape, territory, and nest site level, for example, can have profound effects on population demographics and individual fitness and thereby influence habitat choice (Martin 1992, 1998, 2001; Donovan et al. 1995; Lloyd et al. 2005). Nest predation risk can clearly influence decisions by females of where to nest locally (Marzluff 1988; Forstmeier and Weiss 2004). However the influence of nest predation on habitat decisions at larger spatial scales (i.e., territory choice) remains unclear, in part because direct experimental tests of its importance are conspicuously lacking.

Here, we examine whether individuals from 12 passerine species are able to assess and choose habitats based on variation in nest predation risk across a landscape. Specifically, we experimentally reduced nest predation risk and measured subsequent settling patterns of returning migrants compared to resident species that settle before predator manipulations. We asked whether migratory birds make settlement decisions based on reliable cues such as nest predator abundance and/or vocalizations of predators, independent of other agents of selection such as food availability or microclimate (Cody 1985; Martin 1995; Roos and Pärt 2004).

We utilized two metrics of habitat preference: order of occupation and population density (Fretwell 1972; Cody 1985; Petit and Petit 1996; but see Van Horne 1983). Each of these measures addresses different components of choice, and by using both, we enhance our understanding of habitat selection. Theory predicts that the first individuals to arrive in a landscape will choose to settle in areas 
of highest quality (Fretwell 1972). Thus, we assessed habitat choice by comparing the relative date that areas with and without nest predators were first occupied. This enabled us to determine the influence of nest predation risk on settlement choice independent of the confounding influences of conspecifics. Conspecifics may affect settlement decisions both positively (i.e., conspecific attraction; Ward and Schlossberg 2004) and negatively (i.e., territory defense, nest site limitation, food limitation; Fretwell 1972; Cody 1985; Martin 1995; Martin and Martin 2001; Richardson and Burke 2001) and obscure the importance of nest predation in determining where an individual would choose to settle, given no other constraints or biases. We predicted that individuals would settle first in areas with reduced nest predation risk to maximize their potential nest success.

While settlement order may indicate the importance of nest predation in shaping settlement decisions under ideal conditions, these conditions are rare. Individuals arriving after the settlement of the first individual must also weigh the costs of settling with other conspecifics, including costs from competition for food, mates, and nest sites, all known to increase with increasing density (Fretwell 1972; Cody 1985; Martin 1995; Martin and Martin 2001; Richardson and Burke 2001). Ultimately, individuals must balance nest predation risk against other costs in their choice of breeding habitats. To reduce other sources of environmental variation that could confound settlement decisions, we applied our predator removal treatment to 10 plots that were paired with 10 control plots of historically similar bird and plant assemblages but had intact predator communities. We then tested whether birds would accept increased competition in favor of reduced nest predation risk by preferentially settling earlier and at higher densities in areas of reduced nest predation risk.

\section{Methods}

Study Area and Species

We studied the influence of nest predation risk on habitat preference of migratory birds breeding in 20 snowmelt drainages located along the Mogollon Rim in central Arizona from 2001 to 2004 . Vegetation is typical of a western mixed conifer forest (Martin 1998). This system is particularly appropriate for examining habitat preference in relation to nest predation risk because nest predation accounts for $98 \%$ of nest failure (Martin 1998). Returning migrants are easily detected to measure settlement date, and densities are easily measured (Martin 2001). In addition, the predator community is simple, making manipulation of nest predation risk feasible (Fontaine and Martin 2006).
We examined habitat preference for eight Neotropical migrants that returned after nest predators had been experimentally reduced in portions of the landscape. These species represent a diverse continuum of ecological and behavioral characteristics and are known to differ in nest predation risk (Martin 1995, 1998; Fontaine and Martin 2006). In all figures, species are referenced by their fourletter American Ornithological Union codes: OCWAorange-crowned warbler (Vermivora celata), VIWA-Virginia's warbler (Vermivora virginiae), RFWA-red-faced warbler (Cardellina rubrifrons), GHJU-gray-headed junco (Junco hyemalis caniceps), HETH-hermit thrush (Catharus guttatus), AMRO-American robin (Turdus migratorius), COFL-Cordilleran flycatcher (Empidonax occidentalis), and HOWR-house wren (Troglodytes aedon). We also examined the response of four resident species that chose nesting habitats before experimental reductions of nest predators and therefore should not respond to the experiment. This enabled us to use the density of these species as a control independent of our treatment. These species included WBNU-whitebreasted nuthatch (Sitta carolinensis), RBNU-redbreasted nuthatch (Sitta canadensis), MOCH-mountain chickadee (Poecile gambeli), and BRCR-brown creeper (Certhia americana).

\section{Nest Predator Removals}

We conducted a predator removal experiment to alter nest predation risk across the landscape (see Fontaine and Martin 2006 for detailed description). We removed predators from 10 drainages (hereafter "plots") that were 5-10 ha in size (removal plots) to compare with 10 neighboring and similarly sized drainages with intact predator communities (control plots). We paired plots based on 20 years of prior data that permitted us to match plots with similar bird, predator, and plant assemblages (Fontaine and Martin 2006). Control and removal plots were spatially paired to minimize possible spatial influences but were separated by at least one intervening drainage to buffer against possible carryover effects of removals on control plots. Study drainages were 100-150 m wide with an intervening ridge of similar width, so even with an intervening drainage, treatment and control drainages were separated by only about $450 \mathrm{~m}$ and were well within sampling distances of returning migrants. We removed predators from the same plots all 4 years of the study to maximize effect size.

Removals began before the arrival of any female migrant birds to the study site and continued throughout the breeding season. The primary nest predators for which removals were conducted included red squirrel (Tamaiasciurus hudsonicus), gray-neck chipmunk (Eutamias cinereicollis), deer mouse (Peromyscus maniculatus), white- 
footed mouse (P. leucopus), and Steller's jay (Cyanocitta stelleri; Martin 1992). Additional predators exist within the community but at very low densities. To determine the effectiveness of removals, we measured nest predation rates and assessed nest predator abundance throughout the breeding season by conducting aural surveys for jays and squirrels (Fontaine and Martin 2006).

\section{Nest Finding and Monitoring}

We located and monitored nests to determine nest initiation dates (day the first egg is laid in a nest) and nest predation rates. Nests on both control and removal plots were located using standard techniques (Martin and Guepel 1993). We determined the exact initiation dates for all nests found before clutch completion. Incubation periods are well established for all study species (Martin 2002), allowing us to increase our sample size by backdating nests found during the incubation period for which exact hatch date was observed. We used Mayfield estimates of nest predation rates (Mayfield 1961, 1975; Hensler and Nichols 1981), which we compared between treatments and across years using a repeated-measures ANOVA.

\section{Response Variables}

We assessed habitat preference by comparing the order of occupation and density (Fretwell 1972; Cody 1985; Petit and Petit 1996). Specifically, we examined the date that the first female of each species arrived on each study plot and the density of breeding pairs for each species. We focused on female habitat preference because the risk of nest predation is greatest during the egg laying and incubation periods (Martin et al. 2000) when the majority of reproductive investment is by females. Selection should act strongly on females to choose nesting habitats that limit the risk of nest predation during these critical periods (Martin 1992, 1998; Martin et al. 2000).

We monitored plots daily from before any females arrived at the study site and recorded the date that the first female settled on each study plot. We considered females to have settled on a plot if a previously single male was verified to have paired with a female and maintained that pairing for 3 consecutive days. Females that arrived on plots were easily detected because they are not particularly cryptic before nesting, and males exhibit distinct changes in singing and courtship behaviors indicating the presence of a female (J. J. Fontaine and T. E. Martin, personal observation; Gibbs and Wenny 1993). Because of the intensity of these surveys, we focused on two species, which we chose because they arrived early (OCWA) and late (COFL) at the study site. We also compared the nest initiation date of the first nest for each female on a plot as an indicator of when she arrived, settled, and initiated breeding. These data may be particularly important because in passerines, earlier nest initiation generally increases fitness (Arcese and Smith 1988; Nilsson 2000). We did not include the resident species in this analysis because of the difficulty in accessing cavity nests and determining exact nest initiation dates for these species. The arrival and nest initiation dates allow us to examine preference based on priority of settlement and breeding decisions, although both measures are potentially affected by issues of female site fidelity. Older females are usually the first to arrive in this system and are the most likely to be site faithful (J. J. Fontaine and T. E. Martin, personal observation; Switzer 1993). Thus, our examination of habitat choice is potentially conservative because of constraints from site fidelity.

We also assessed the density of breeding pairs as an index of habitat choice. Density may not always be a proper indicator of habitat quality, but it is a good indicator of preference (Van Horne 1983). In this experiment, density may indicate both preference and habitat quality because we altered an environmental factor known to affect fitness. We created territory maps for each species on each plot by intensively surveying the plots throughout the breeding season to assess breeding density. Maps included pairs of each species known to be breeding throughout the breeding season.

As another index of density and breeding activity, we also randomly sampled plots for singing males throughout the breeding season. Tape recorders were paired and randomly placed on both control and removal plots every fourth day of the season for a total of 23 days and sampled starting at sunrise and every half-hour after for a total of six samples per day. Sampling consisted of a 1-min survey to determine the presence or absence of each species. We did not sample white-breasted nuthatches or brown creepers for this comparison because they were rare and difficult to census accurately. For all of the response variables, we tested for differences between treatments across years using a repeated-measures ANOVA.

\section{Results}

Nest predator removals resulted in a reduction in nest predation rates for resident and migratory species (fig. $1 a$, $1 b ; F=5.092$, df $=1,22, P=.034)$. As expected, the density of resident species did not differ between treatments since residents established territories every year before our predator manipulations (fig. $1 c ; F=0.014$, $\mathrm{df}=1,8, P=.9$ ). However, nesting densities of migratory species were significantly greater on removal versus control plots (fig. $1 d ; F=6.629$, df $=1,12, P=.024$ ). In addition, the singing activity of males of all species, 


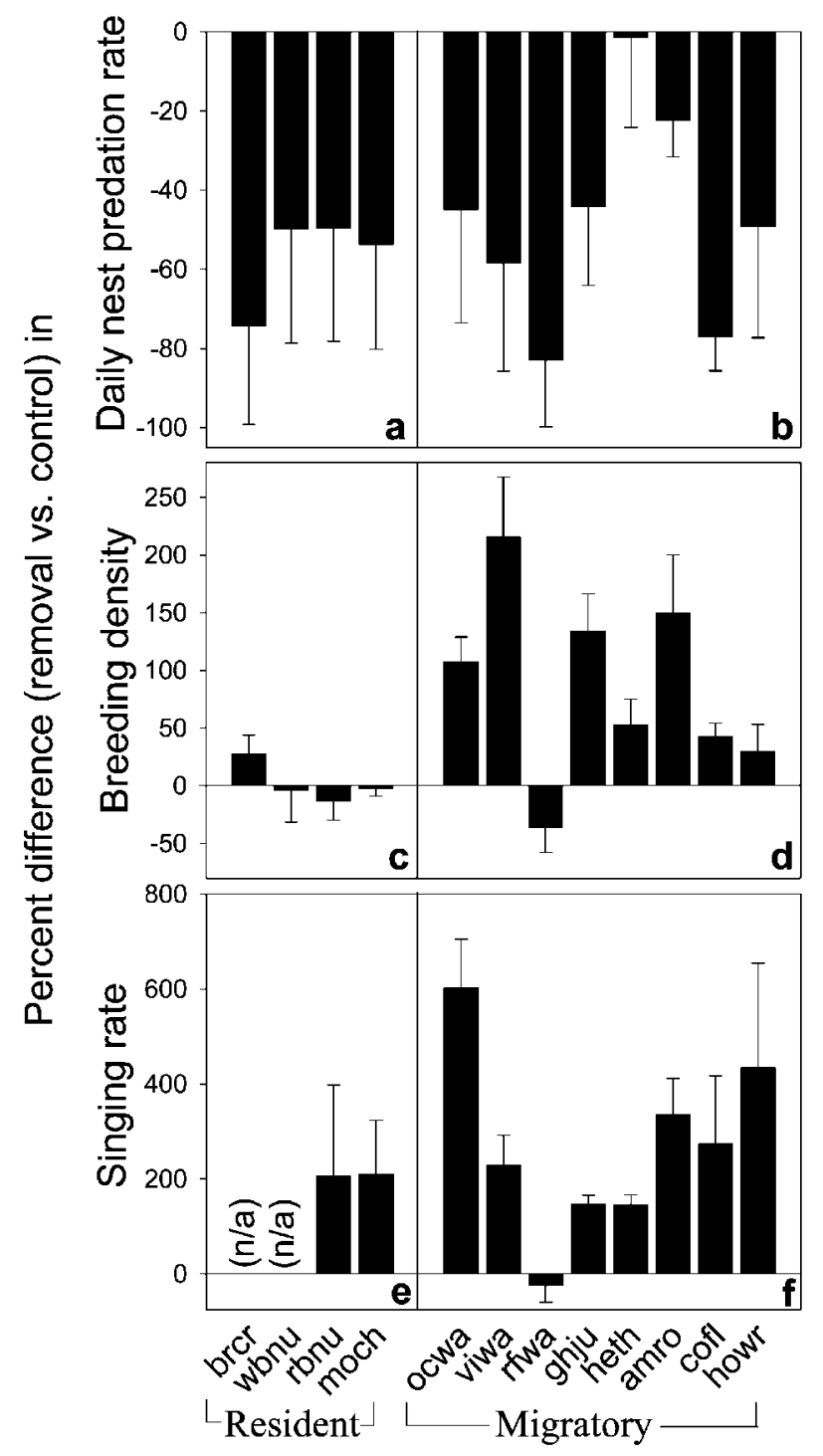

Figure 1: Predator removals resulted in a reduction in nest predation rates that led to an increase in breeding density and singing rates. Responses are illustrated by percent difference ([removal - control]/control $\times 100$ ). Predator removals resulted in a reduction in daily mortality rates for both resident $(a)$ and migratory $(b)$ species. Resident species $(c)$ did not differ in density between treatments, but migratory $(d)$ species preferentially settled on removal plots. Male song frequency was greater on removal plots than controls for both resident $(e)$ and migratory $(f)$ species. Data were not collected for all species for all variables (indicated by n/a). Error bars represent SEM across years. See "Study Area and Species" for definitions of bird name abbreviations.

both resident and migratory, was greater on removal plots (fig. $1 e, 1 f ; F=17.166, \mathrm{df}=1,18, P=.001$ ).

While predator removals influenced the density of nesting migrants, arrival dates of orange-crowned warblers and cordilleran flycatchers did not differ between treatments $(F=0.006, \mathrm{df}=1,22, P=.9)$. In addition, there were no clear treatment effects across all migrants for the date that the first nest of each species was initiated on each plot (fig. $2 a ; F=0.458$, df $=1,27, P=.5$ ) or the mean nest initiation date for each species on each plot (fig. $2 b$; $F=0.732, \mathrm{df}=1,26, P=.4)$.

\section{Discussion}

Habitat selection studies in birds are frequently correlational, often relating vegetation indexes to timing of nest initiation or breeding density. This type of study is an important first step to understanding habitat selection, but 


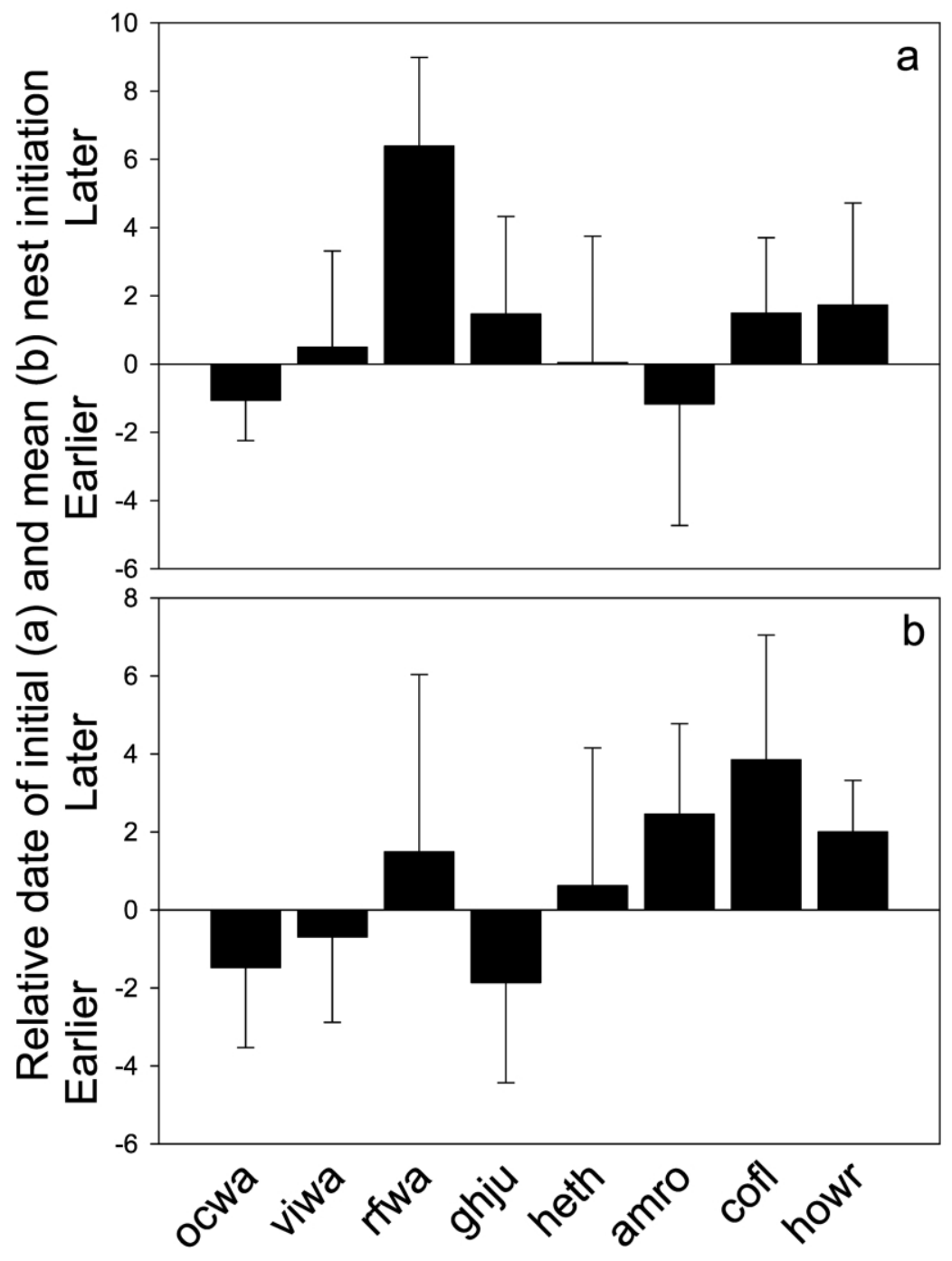

Figure 2: Predator removals did not lead to changes in phenology. Average relative date (removal - control) of first nest initiation (a) and mean nest initiation $(b)$ did not differ between treatments. Error bars represent SEM across years. See "Study Area and Species" for definitions of bird name abbreviations.

understanding the causal bases of habitat choice is limited by at least two inherent problems. First, variation in vegetation at local and landscape levels can be associated with variation in a multitude of selection agents, including but not limited to microclimate, food availability, adult predation risk, and nest predation risk. Distinguishing which of these is driving habitat selection can be nearly impossible using only vegetation correlates. Second, although vegetation may correlate with important sources of selection, this does not mean it is a perfect indicator because food, predators, and microclimate all can vary independent of vegetation. Here we minimized these potential confounding effects by choosing adjacent plots with sim- ilar vegetation composition and structure while experimentally manipulating one particularly important agent of selection-nest predation —and testing its influence on habitat selection.

One of the most important components of selecting a habitat is using a cue that is readily available and reliably indicates habitat quality (Doligez et al. 2003; Danchin et al. 2004). In this system, vocal cues of red squirrels and Steller's jays are readily available and easy to assess. A reduction in frequency of these cues (Fontaine and Martin 2006) corresponded to a reduction in actual nest predation risk (fig. $1 a, 1 b$ ). This finding is important because it gives us a reasonable expectation that birds may distinguish be- 
tween habitats of different quality based on such cues and choose habitats with reduced risk of nest predation.

Indeed, birds did respond to the experimentally induced landscape-level changes in nest predation risk. Although we failed to find any consistent patterns of settlement priority and nest initiation on removal plots (fig. 2), the strong increase in density of migratory species clearly suggests preference for plots with reduced nest predation risk (fig. 1c,1d) despite potentially increased costs of competition (Martin and Martin 2001). So why might we find a density response but no changes in when individuals settle and begin breeding? First, older and more successful individuals tend to arrive and settle first and are generally faithful to sites they occupied in previous years, especially if they were successful (J. J. Fontaine and T. E. Martin, personal observation; Switzer 1993; Haas 1998; Porneluzi 2003). Second, many individuals in this system arrive nearly synchronously, quickly exceeding the capacity of the removal plots and necessarily spilling into control plots (J. J. Fontaine and T. E. Martin, personal observation). These natural patterns limit our ability to detect differences in arrival date and nest initiation date between treatments. Measures of density are not sensitive to these problems and therefore may better indicate true preference in this system.

The large increase in density of migratory species on plots with reduced nest predation risk (fig. 1d) suggests that birds are able to assess nest predation risk and modify habitat choice. An alternative possibility is that the increase in density on removal plots may reflect increased survival of young that subsequently return to breed on their natal plots. However, this alternative seems unlikely. First, the pattern of increased nesting density was consistent across all years of the study. Even in the first year of the treatment, density for migratory species was greatest on removal plots $(t=-1.651, P=.072)$, despite similar nest success between plots in the previous year. Second, we failed to detect any increase in density in resident species despite increased nest success in these species as well. Finally, natal site fidelity is extremely low in migrants in this system. From 2001 to 2003, we banded nearly 400 fledging-age nestlings, representing seven migratory species in both removal and control plots. Despite intensive efforts to locate these individuals on the study site from 2002 to 2004, we found only three individuals, representing less than $1 \%$ of the nestlings that were banded. Of these, none returned to their natal plot. Thus, although increased productivity and high natal site fidelity is important for determining density in some systems (Cote and Sutherland 1997; Clark and Shutler 1999), it appears unable to explain the increase in density seen here.

As we expected, resident species (fig. 1c) did not respond to the reduction in nest predation risk because they had already made habitat decisions before the initiation of the experiment each year. The fact that we found no difference in resident abundance between treatments suggests that we chose well-paired study plots that eliminated many potential confounding variables. The lack of response to the treatment by resident species might also reflect the fact that all of the resident species are cavity nesters, which may face greater limitation in nest site availability than open-nesting species (Martin 1993; but see Martin and Martin 2001). Yet, two of the migratory species also use cavities and show a density response (fig. $1 b$ ), suggesting that nest site limitation alone cannot explain the lack of response by resident species.

We also found that male singing activity was higher on plots with reduced nest predation risk (fig. $1 e, 1 f$ ). Increased singing activity may simply reflect increased density and therefore increases in territory defense costs as males are forced to sing more in response to increased interactions between males (Penteriani 2003; Goretskaia 2004; but see Tarof et al. 1998), but it may also reflect increased activity in safer environments (Martin et al. 2000). This latter possibility is further supported by the fact that singing activity increased for resident species that did not increase in density on removal plots (i.e., fig. $1 c$, 1e), as well as species that increased in density (fig. $1 d$, $1 f$ ). Alternatively, changes in singing activity by species that did not increase in density may reflect increased signaling of high-quality territories, the importance of singing in limiting conspecific density in quality habitats (see above), or the potential for heterospecific competition with species that did increase in density. Regardless, increases in singing activity signify the importance of nest predation in shaping community interactions, even among species that have limited overlap in nest sites or nest predation risk.

Our study has shown that the risk of nest predation can have profound effects on habitat selection decisions made by migrating birds. Moreover, the significant decrease in actual nest predation rates on individuals settling on predator removal plots suggests that these decisions represent adaptive responses to local variation in an important agent of selection. These findings reinforce the importance of variation in nest predation risk in shaping avian community structure and function through the process of habitat selection.

\section{Acknowledgments}

We thank A. Chalfoun, K. Decker, D. Emlen, R. Fletcher, J. Maron, D. Reznick, and two anonymous reviewers for comments and support and numerous field assistants for their hard work. We also thank M. Martel, without whom none of this would have been possible, and C. Taylor and 
the Coconino National Forest staff for their support, as well as G. Witmer and the National Wildlife Research Center for the use of their equipment. This work was supported by funding to T.E.M. from the U.S. Geological Survey Climate Change Research program and the National Science Foundation (DEB-9981527, DEB-0543178) and funding to J.J.F. from the American Ornithological Union and Sigma Xi.

\section{Literature Cited}

Arcese, P., and J. N. M. Smith. 1988. Effects of population density and supplemental food on reproduction in song sparrows. Journal of Animal Ecology 57:119-136.

Blaustein, L., M. Kiflawi, A. Eitam, M. Mangel, and J. E. Cohen. 2004. Oviposition habitat selection in response to risk of predation in temporary pools: mode of detection and consistency across experimental venue. Oecologia (Berlin) 138:300-305.

Casey, T. M. 1976. Activity patterns, body temperature and thermal ecology in two desert caterpillars (Lepidoptera: Sphingidae). Ecology 57:485-497.

Clark, R. G., and D. Shutler. 1999. Avian habitat selection: pattern from process in nest-site use by ducks? Ecology 80:272-287.

Cody, M. L., ed. 1985. Habitat selection in birds. Academic Press, New York.

Cote, I. M., and W. J. Sutherland. 1997. The effectiveness of removing predators to protect bird populations. Conservation Biology 11: 395-405.

Danchin, E., L. Giraldeau, T. J. Valone, and R. H. Wagner. 2004. Public information: from nosy neighbors to cultural evolution. Science 305:487-491.

Doligez, B., C. Cadet, E. Danchin, and T. Boulinier. 2003. When to use public information for breeding habitat selection? the role of environmental predictability and density dependence. Animal Behaviour 66:973-988.

Donovan, T. M., F. R. Thompson, J. Faaborg, and J. R. Probst. 1995. Reproductive success of migratory birds in habitat sources and sinks. Conservation Biology 9:1380-1395.

Fontaine, J. J., and T. E. Martin. 2006. Parent birds assess nest predation risk and adjust their reproductive strategies. Ecology Letters 9:428-434.

Forstmeier, W., and I. Weiss. 2004. Adaptive plasticity in nest-site selection in response to changing predation risk. Oikos 104:487499.

Fretwell, S. D. 1972. Populations in a seasonal environment. Princeton University Press, Princeton, NJ.

Gibbs, J. P., and D. G. Wenny. 1993. Song output as a population estimator: effect of male pairing status. Journal of Field Ornithology 64:316-322.

Goretskaia, M. I. 2004. Song structure and singing behaviour of willow warbler Prylloscopus trochilus acredula in populations of low and high density. Bioacoustics 14:183-195.

Haas, C. A. 1998. Effects of prior nesting success on site fidelity and breeding dispersal: an experimental approach. Auk 115:929-936.

Hensler, G. L., and J. D. Nichols. 1981. The Mayfield method of estimating nesting success: a model, estimators and simulation results. Wilson Bulletin 93:42-53.

Jaenike, J., and T. D. Holt. 1991. Genetic variation for habitat pref- erence: evidence and explanations. American Naturalist 137(suppl.):S67-S90.

Kessler, A., and I. T. Baldwin. 2002. Manduca quinquemaculata's optimization of intra-plant oviposition to predation, food quality, and thermal constraints. Ecology 85:2094-2099.

Lloyd, P., T. E. Martin, R. L. Redmond, U. Langner, and M. M. Hart. 2005. Linking demographic effects of habitat fragmentation across landscapes to continental source-sink dynamics. Ecological Applications 15:1504-1514.

Martin, P. R., and T. E. Martin. 2001. Ecological and fitness consequences of species coexistence: a removal experiment with wood warblers. Ecology 82:189-206.

Martin, T. E. 1992. Breeding productivity considerations: what are the appropriate habitat features for management? Pages 455-473 in J. M. Hagan and D. W. Johnston, eds. Ecology and conservation of Neotropical migrants. Smithsonian Institution, Washington, DC.

1993. Evolutionary determinants of clutch size in cavitynesting birds: nest predation or limited breeding opportunities? American Naturalist 142:937-946.

- 1995. Avian life-history evolution in relation to nest sites, nest predation, and food. Ecological Monographs 65:101-127.

1998. Are microhabitat preferences of coexisting species under selection and adaptive? Ecology 79:656-670.

- 2001. Abiotic vs. biotic influences on habitat selection of coexisting species: climate change impacts? Ecology 82:175-188.

. 2002. A new view for avian life history evolution tested on an incubation paradox. Proceedings of the Royal Society B: Biological Sciences 269:309-316.

Martin, T. E., and G. R. Guepel. 1993. Nest-monitoring plots: methods for locating nests and monitoring success. Journal of Field Ornithology 64:507-519.

Martin, T. E., J. Scott, and C. Menge. 2000. Nest predation increases with parental activity: separating nest site and parental activity effects. Proceedings of the Royal Society B: Biological Sciences 267: 2287-2294.

Marzluff, J. M. 1988. Do pinyon jays alter nest placement based on prior experience? Animal Behaviour 36:1-10.

Mayfield, H. 1961. Nesting success calculated from exposure. Wilson Bulletin 73:255-261.

- 1975. Suggestions for calculating nest success. Wilson Bulletin 87:456-466.

Morris, D. W. 2003. Toward an ecological synthesis: a case for habitat selection. Oecologia (Berlin) 136:1-13.

Nilsson, J. 2000. Time-dependent reproductive decisions in the blue tit. Oikos 88:351-361.

Petit, L. J., and D. R. Petit. 1996. Factors governing habitat selection by prothonotary warbler: field tests of the Fretwell-Lucas models. Ecological Monographs 66:367-387.

Penteriani, V. 2003. Breeding density affects the honesty of bird vocal displays as possible indicators of male/territory quality. Ibis 145: E127-E135.

Porneluzi, P. A. 2003. Prior breeding success affects return rates of territorial male ovenbirds. Condor 105:73-79.

Richardson, D. S., and T. Burke. 2001. Extrapair paternity and variance in reproductive success related to breeding density in Bullock's orioles. Animal Behaviour 62:519-525.

Rieger, J. F., C. A. Binckley, and W. J. Resetarits. 2004. Larval performance and oviposition site preference along a predation gradient. Ecology 85:2094-2099. 
Roos, S., and T. Pärt. 2004. Nest predators affect spatial dynamics of breeding red-backed shrikes (Lanius collurio). Journal of Animal Ecology 73:117-127.

Smith, C. J., J. D. Reynolds, and W. J. Sutherland. 2000. Population consequences of reproductive decisions. Proceedings of the Royal Society B: Biological Sciences 267:1327-1334.

Switzer, P. V. 1993. Site fidelity in predictable and unpredictable habitats. Evolutionary Ecology 7:533-555.

Tarof, S. A., B. J. M. Stutchbury, W. H. Piper, and R. C. Fleischer. 1998. Does breeding density covary with extra-pair fertilizations in hooded warblers? Journal of Avian Biology 29:145-154.
Tschanz, B., E. Schmid, and S. Bacher. 2005. Host plant exposure determines larval vulnerability: do prey females know? Functional Ecology 19:391-395.

Van Horne, B. 1983. Density as a misleading indicator of habitat quality. Journal of Wildlife Management 47:893-901.

Ward, M. P., and S. Schlossberg. 2004. Conspecific attraction and the conservation of territorial songbirds. Conservation Biology 18: $519-525$.

Associate Editor: Tim Coulson Editor: Jonathan B. Losos 